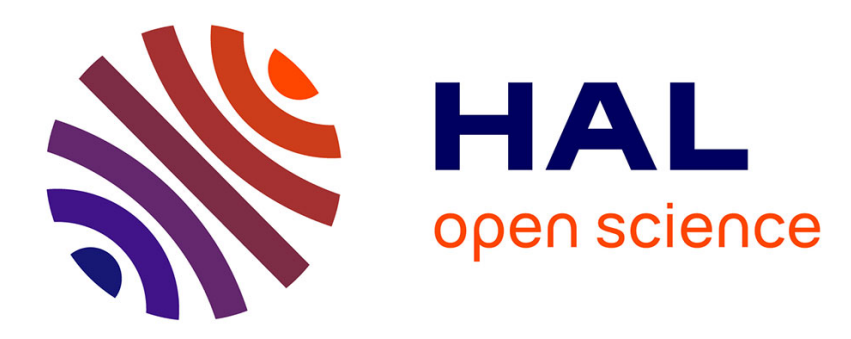

\title{
XAFS Study on the Microstructure of Mo/Si Multilayers
}

S. Wei, L. Wu, W. Liu, Zi. Wu

\section{To cite this version:}

S. Wei, L. Wu, W. Liu, Zi. Wu. XAFS Study on the Microstructure of Mo/Si Multilayers. Journal de Physique IV Proceedings, 1997, 7 (C2), pp.C2-1249-C2-1250. 10.1051/jp4:19972217 . jpa-00255290

\section{HAL Id: jpa-00255290 https://hal.science/jpa-00255290}

Submitted on 1 Jan 1997

HAL is a multi-disciplinary open access archive for the deposit and dissemination of scientific research documents, whether they are published or not. The documents may come from teaching and research institutions in France or abroad, or from public or private research centers.
L'archive ouverte pluridisciplinaire HAL, est destinée au dépôt et à la diffusion de documents scientifiques de niveau recherche, publiés ou non, émanant des établissements d'enseignement et de recherche français ou étrangers, des laboratoires publics ou privés. 


\title{
XAFS Study on the Microstructure of Mo/Si Multilayers
}

\author{
S. Wei, L. Wu, W. Liu and Zi. Wu \\ Center for Fundamental Physics, and Hefei Synchrotron Radiation Laboratory, \\ University of Science \& Technology of China, Hefei 230026, P.R. China
}

\begin{abstract}
X}$-ray absorption fine structure(XAFS) was used to investigate the structure of Mo/Si multilayers from $20 \AA$ to $3000 \AA$ period value. The XAFS results show the structural disorder of Mo atom neighbor environment is significantly increased as the thickness of Mo layer is thinner. For $20 \AA$ and $50 \AA$ period Mo/Si multilayers, the polycrystalline Mo layer vanish, the first neighbor coordination of $\mathrm{Mo}$ atom is mainly surrounded by $\mathrm{Si}$ atoms, the intended small period structure were drastically destroyed by interdiffusion. The mixed layer is amorphous MoSi2. XAFS results confirm that there is no clear period structure in very small period $\mathrm{Mo} / \mathrm{Si}$ multilayer.
\end{abstract}

\section{Introduction}

In recent years, there has been accelerating interest in period $\mathrm{Mo} / \mathrm{Si}$ multilayers used as reflective and dispersive elememts at soft $\mathrm{X}$-ray waveband. It was reported that the reflectivities of $\mathrm{Mo} / \mathrm{Si}$ mirrors, which were fabricated for the wavelength region of $125 \sim 250 \AA[1]$, can reach $50 \%$. The structure studies of $\mathrm{Mo} / \mathrm{Si}$ multilayer revealed that there were clear interfaces between $\mathrm{Si}$ and Mo layer, a-Si and polycrystalline Mo in these samples[1,2]. However, the internal microstructure of the individual Mo layers and Mo/Si interfaces are not known clearly now. In this short report, Our aims were to study the local structural change of Mo atomic neighbor environment of Mo/Si multilayers with the period decrease by XAFS.

\section{Experimental}

Mo/Si multilayers with periods of $20 \AA, 50 \AA$ and $200 \AA$ were deposited on cleaned glass substrates with a magnetron sputtering apparatus. The Ar sputtering pressure was $1.00 \mathrm{~Pa}$. Deposited rates of Si and Mo were $32 \AA / \mathrm{min}$ and $27 \AA / \mathrm{min}$, respectively. The thickness ratio of $\mathrm{Mo}$ and $\mathrm{Si}$ is $1: 2$ in all Mo/Si multilayers. Mo film with thickness of $3000 \AA$ was also fabricated with deposition. The Mo K-edge XAFS spectra of the peeled samples were measured on the beam line of 4 W1B of Beijing Synchrotron Radiation Facility. The electron beam energy is $2.2 \mathrm{GeV}$ and maximumstored current is $50 \mathrm{~mA}$. Data were collected with a fixed exit monochromator using two flat $\mathrm{Si}(111)$ crystals. Data were collected in transmission mode using ion chamber fill with Ar gas at room temperature.

\section{Results and Discussion}

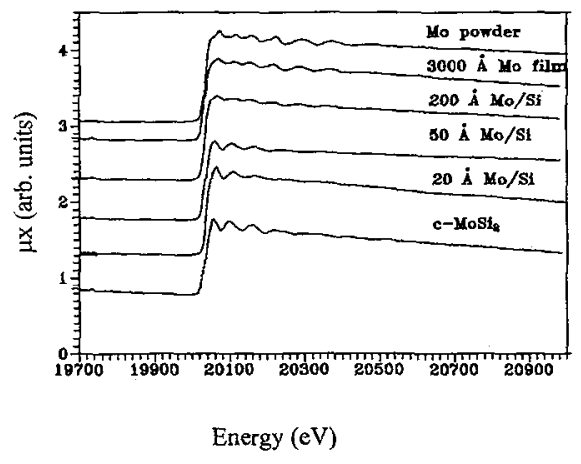

Fig.1 Mo K-edge Absorption Spectra of Mo/Si Multilayers

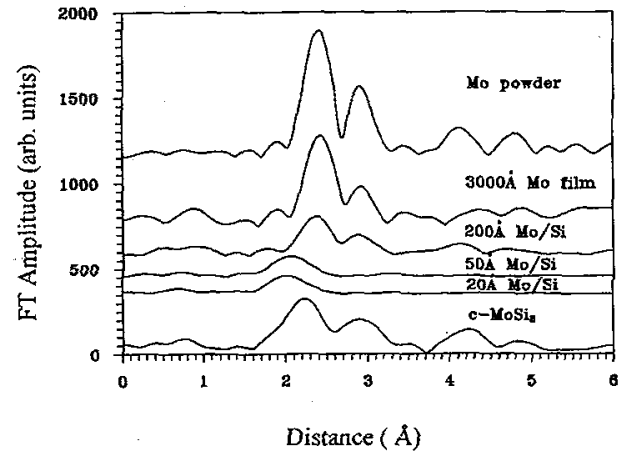

Fig.2 The RDF of Mo Atom of Mo-Si Multilayers 
The Mo K-edge absorption spectra of Mo/Si multilayers, crystalline Mo powder and $\mathrm{MoSi}_{2}$ film are shown in Fig. 1. It can be found that intensity and frequency of the oscillatory signal decreased for small period $\mathrm{Mo} / \mathrm{Si}$ multilayers. In the $400 \mathrm{eV}$ above the Mo K absorption edge, there are six oscillation peaks for Mo powder and $3000 \AA$ Mo film, only two peaks for $50 \AA$ and $20 \AA$ period $\mathrm{Mo} / \mathrm{Si}$ multilayers. The absorption spectra of $20 \AA$ and $50 \AA \mathrm{Mo} / \mathrm{Si}$ multilayers are evidently different from that of $3000 \AA \mathrm{Mo}$ film. Otherwise, they are similar to that of $\mathrm{MoSi}_{2}$ in the 0 to $200 \mathrm{eV}$ region above Mo absorption edge except the amplitude of modulation is a little lower.

Fig. 2 shows the radial distribution functions (RDF) of samples, which were obtained from fast Fourier transformation of their $\chi(\mathrm{k}) \mathrm{k}^{3}$. There are two stronger coordination peaks at $2.40 \AA$ and $2.90 \AA$ in the RDF of Mo powder, it may contribute to the first shell $R=2.72 \AA, N=8$, and the second shell $R=3.14 \AA, N=6$ respectively. In the $R D F$ of $M_{0} \dot{i}_{2}$ film, the first main peak is that Mo is coordinated by ten $\mathrm{Si}$ atoms, $\mathrm{R}_{\mathrm{Mo}-\mathrm{Si}}=2.62 \AA$; the second stronger peak is that Mo is coordinated by four Mo atoms, $\mathrm{R}_{\mathrm{Mo}-\mathrm{Mo}}=3.20 \AA$. Compared with $3000 \AA \mathrm{Mo}$ film, the peak amplitude of the first and second Mo coordination shell decrease drastically for the $200 \AA$ period $\mathrm{Mo} / \mathrm{Si}$ multilayer, but their $\mathrm{R}$ values are equal. It suggests that the Mo local structure of $\mathrm{Mo} / \mathrm{Si}$ multilayer with $200 \AA$ period keeps the main characteristic of metallic Mo, their differences are structural disorder. The RDF shapes of both $20 \AA$ and $50 \AA$ period $\mathrm{Mo} / \mathrm{Si}$ multilayers are the same, which are evidently different from that of $200 \AA \mathrm{Mo} / \mathrm{Si}$ multilayer, only one weak amplitude peak appears at $R=2.00 \AA$. It indicates that Mo is complete amorphicity for the $20 \AA$ and $50 \AA$ period Mo/Si multilayers because peaks of farther distant neighbors are absent.

For systems having a high degree of crystalline order or small disorder as the $3000 \AA$ Mo film, the pair distribution function of neighbor atoms around the absorbing atom can be assumed as a symmetric Gaussian function:

$$
\mathrm{g}(\mathrm{R})=\left(2 \pi \sigma^{2}\right)^{-1 / 2} \exp \left[-\left(\mathrm{R}-\mathrm{R}_{0}\right)^{2} / 2 \sigma^{2}\right]
$$

The expression of XAFS interference function as:

$$
\chi(k)=\Sigma_{j} N_{j} F_{j}(k) S_{0}{ }^{2}(k) / k_{j}{ }^{2} \cdot \exp (-2 R / \lambda(k)) \exp \left(-2 k^{2} \sigma_{j}^{2}\right) \cdot \sin \left[2 k R_{j}+\delta(k)\right]
$$

For disordered systems, the Gaussian pair distribution function is unvalid to express the neighbor atoms distribution from central atom. The asymmetric distribution function of disordered Mo/Si multilayers with $20 \AA$ to $50 \AA$ period is designed as:

$$
\begin{array}{cl}
\mathrm{g}(\mathrm{R}) \operatorname{asym}=\left(1 / \sigma_{\mathrm{S}}\right) \exp \left[-\left(\mathrm{R}-\mathrm{R}_{0}\right) / \sigma_{\mathrm{S}}\right] & \begin{array}{l}
\mathrm{R} \geq \mathrm{R}_{0} \\
\mathrm{R}<\mathrm{R}_{0}
\end{array} \\
\chi(\mathrm{k})_{1}=\mathrm{N}_{1} \mathrm{~F}(\mathrm{k}) \mathrm{S}_{0}{ }^{2}(\mathrm{k}) / \mathrm{kR}_{0}{ }^{2} \cdot 1 /\left(1+4 \mathrm{k}^{2} \sigma_{\mathrm{s}}{ }^{2}\right)^{1 / 2} \cdot \exp (-2 \mathrm{R} / \lambda(\mathrm{k})) \exp \left(-2 \mathrm{k}^{2} \sigma_{\mathrm{t}}{ }^{2}\right) \cdot \sin \left[2 \mathrm{kR}+\delta(\mathrm{k})+\operatorname{arctg} 2 \mathrm{k} \sigma_{\mathrm{s}}\right]
\end{array}
$$

\begin{tabular}{|c|c|c|c|c|c|c|c|c|c|c|c|}
\hline \multirow{2}{*}{\multicolumn{2}{|c|}{ sample }} & \multirow{3}{*}{$\begin{array}{l}\text { pair } \\
\text { Mo-Mo }\end{array}$} & \multirow{3}{*}{$\begin{array}{l}\mathrm{R}(\AA) \\
2.73\end{array}$} & \multirow{3}{*}{$\begin{array}{c}\sigma_{\mathrm{t}}(\AA) \\
0065\end{array}$} & \multicolumn{4}{|c|}{ first neighbor coordination shell } & \multirow{3}{*}{$\sigma_{t}(\AA)$} & \multirow{3}{*}{$\sigma_{\mathrm{S}}(\AA)$} & \multirow{3}{*}{$\mathrm{N}$} \\
\hline & & & & & $\sigma_{\mathrm{S}}(\AA)$ & $\mathrm{N}$ & pair & $\mathrm{R}(\AA)$ & & & \\
\hline $3000 \AA$ & Mo film & & & & $\sim 0$ & $8.0 \pm 0.5$ & & & & & \\
\hline $200 \AA$ & $\mathrm{Mo} / \mathrm{Si}$ & Mo-Mo & 2.71 & 0.091 & $\sim 0$ & $6.2 \pm 0.5$ & $\mathrm{Mo}-\mathrm{Si}$ & 2.60 & 0.065 & $\sim 0$ & $1.2 \pm 0.3$ \\
\hline $50 \AA$ & $\mathrm{Mo} / \mathrm{Si}$ & Mo-Si & 2.61 & 0.071 & 0.080 & $5.8 \pm 0.5$ & Mo-Mo & 2.70 & 0.072 & 0.11 & $1.4 \pm 0.3$ \\
\hline $20 \AA$ & $\mathrm{Mo} / \mathrm{Si}$ & Mo-Si & 2.60 & 0.073 & 0.085 & $6.0 \pm 0.5$ & Mo-Mo & 2.69 & 0.075 & 0.12 & $1.5 \pm 0.3$ \\
\hline
\end{tabular}

$\chi(\mathrm{k})_{1}$ is the XAFS function for the first coordination shell. $\sigma_{\mathrm{s}}$ is the root mean square displacement of structural disorder, $\sigma_{1}$ is the thermal disorder, $R_{0}$ is the distance of central atom to the closest packing atom. The differences between equation (2) and (4) are a reduced factor $1 /\left(1+4 \mathrm{k}^{2} \sigma_{\mathrm{S}}^{2}\right)^{1 / 2}$ in amplitude and a term $\operatorname{arctg}\left(2 \mathrm{k} \sigma_{\mathrm{S}}\right)$ in phase shift.

Table 1. The Structural Parameters of Mo/Si Multilayers

The results in table 1 show that the disorder factor $\sigma\left(\sigma=\sigma_{t}+\sigma_{s}\right)$ of Mo atoms increase while the thickness of Mo layer is thinner. Though the main peak $R$ value is contracted $0.4 \AA$ and peak magnitude intensity is many time lower for $20 \AA$ and $50 \AA$ period $\mathrm{Mo} / \mathrm{Si}$ multilayers comparing with $3000 \AA \mathrm{Mo}$ film, we can obtained reasonable structural parameters by assuming the pair distribution function as $\mathrm{g}(\mathrm{R})_{\mathrm{asym}}$. For small period Mo/Si multilayers, the $\sigma_{\mathrm{s}}$ is bigger than the $\sigma_{\mathrm{t}}$ and the first coordination shell of Mo atom is mainly coordinated by $\mathrm{Si}$ atom. It means the interdiffusing region of both Mo and $\mathrm{Si}$ layer is thicker than $16.7 \AA$ the intended thickness of Mo layer, and the structure of mixed layers is considered as amorphous MoSi $\mathrm{i}_{2}$. There are not polycrystalline Mo layer in small period $\mathrm{Mo} / \mathrm{Si}$ multilayers. Fabricating with magnetron sputtering apparatus, it is difficult to obtain a clear interface between Mo and Si layer while the individual layer is thin to about $15 \AA$.

\section{Acknowledgments}

We would like to thank Dr. Tiandou Hu for their help doing XAFS experiments and also thank BSRF for giving us the beam time for XAFS measurement. This work was supported in part by National Natural Science Foundation of China.

\section{References}

[1]. Slaughter,J.M., Schulze D.W., Hill C.R., Miroue A., Slatio R., Watts R.N., Tarrio C., Lucatorto T.B., Krumrey M., Mueller P., and Falco,C.M., J. Appl. Phys. 76,21 444(1994).

[2]. Petford-Long,A.K., Stearns,M.B., Chang,C.H., Nutt,S.R., Ceglio, N.M., and Hawryluk,A.M., J. Appl. Phys., 61, 1422(1987). 